\title{
Notas sobre o conceito e a tragédia de cultura popular. Uma discussão à luz da sociologia simmeliana*
}

\author{
Ronaldo de Oliveira Corrêa ${ }^{1}$ \\ Universidade Federal do Paraná
}

Este ensaio tem por objetivo realizar uma aproximação ao conceito de cultura popular a partir da perspectiva simmeliana ${ }^{2}$. Minha abordagem busca configurar-se na forma ensaistica dos textos estéticos de Simmel. Tomo esta tarefa por concordar com este autor que o conhecimento está impregnado pelo vitalismo das formas sociais e que estas formas não são apreendidas pelo pensamento sistemático e objetivo, mas estrapolam a estes. Assim sendo, a presença da sociologia de Simmel nesta reflexão estabeleçe as pontes para a interpretação às vezes inusitada, de temas prosaicos como o cotidiano e a cultura popular. Inicio o texto com uma breve revisão pontual de um tipo de história da arte Ocidental sobre a constituição da autonomia deste ofício e por conseqüência deste campo. Apoiado neste panorama, ao modo de um instantâneo fotográfico, reflito sobre a tragédia que envolve a cultura popular na sua configuração contemporânea. Encerro este ensaio propondo uma com-figuração da forma do movimento que esta noção realiza.

Palavras-chave: Cultura popular - Simmel - Estética.
This essay aims to achieve an approximation to the concept of popular culture from the perspective of Georg Simmel's sociology. My approach set its bases in the essay form proposed by Simmel in his texts of aesthetic. I agree with this author that knowledge is impregnated by the vitalism of social forms and these forms are not seized by the systematic thinking and goal, but beyond them. Thus, the presence of Simmel's sociology reflection stands the bridges for the interpretation sometimes unusual of prosaic topics as popular culture and everyday life. With these guide lines is possible a new reading of the notion of popular culture. The text starts with a brief review of history of Western art on the establishment of the autonomy of this crafts and by consequence of this field. Based on this background I construct the reflection about the tragedy involving the popular culture in its contemporary setting. End this essay proposing a configuration of the form of the movement that this concept holds.

Keywords: Popular culture- Georg Simmel - Aesthetics.

\footnotetext{
* Notes on the concept and tragedy in popular culture: a simmelian sociology discussion

${ }^{1}$ Doutor em Ciências Humanas, Programa de Pós-Graduação Interdisciplinar em Ciências Humanas/ UFSC. Docente da Universidade Federal do Paraná (olivecorrea@yahoo.com.br)

${ }^{2}$ Georg Simmel nascido em Berlim no ano de 1858, intelectual de origem judia, batizado no protestantismo, estudou Filosofia na Universidade de Berlim. Após uma vida marginal nas academias alemãs é convidado para ser titular de uma cátedra na Universidade de Estrasburgo; Universidade que parmanece até a sua morte em 1918. Postulava para seu pensamento a mobilidade e plasticidade, o que permitiam aproximar-se do objeto a partir de múltiplas direções. Reivindicava o fragmento, ou seja, opunha-se a fixação e acabamento e a toda pretensão de sistema. Sua forma de aproximar-se do objeto de reflexão é marcada pelo ensaio, a subjetividade, a multiplicidades de perspectivas e a eleição de temas não convencionais, como a guerra, dominação, grupo, conflito, círculos sociais, individualidade, espaço, cultura, dinheiro, entre muitos outros. Ou ainda, ricas reflexões sobre temas inusitados como a ponte, a prota, a moldura, a aventura, o segredo, a asa do jarro e outros (ensaios estéticos).
} 


\section{HUMANAS}

\section{Nota prefacial}

耳 ste é um ensaio em processo. Nesta condição de obra em composição,

- tomo a liberdade de inventar ficções possíveis para alegorias antigas. Este esforço que aqui realizo tem por pré-tensão animar a discursão ainda por retomar sobre a cultura popular - suas configurações materiais e teóricas - nos contextos ou intertextos contemporâneos. Ao assim construir a questão que subjaz a este ensaio, exponho o sombreamento de instigantes questões e reflexões sobre a cultura popular (subalterna) realizadas por Mário de Andrade, Florestan Fernandes e outros folcloristas, literatos, sociólogos e antropólogos, realizadas no decorrer do século XX nestas terras brasileiras.

Entradas, saidas e bandeiras
No altar do Espirito Santo
Duas velas se acendeu
Minha amiga fuliôa
Ave Maria já deu
Te alegra fuliôa
Senta o pé na terra fria
Vem ouvir tocar a alvorada
Na capela de Maria

São tambores que esvaziados de uma sonoridade oca, marcam o rítimo. São vozes de mulheres que em coro, repetem a ladainha. São bandeiras que em procissão, dão andamento à função. É o divino Espirito Santo em louvação. É a cultura popular em manifestação.

A Festa do Divino (ABREU, 1999; p. 40-59) é festa antiga, com registros iconográficos e historiográficos que rememoram o século XIX no Brasil. Estes registros expõem os usos das práticas coletivas subalternas (rituais ou seculares), na configuração de uma narrativa identitária nacional (nacionalista) pretensamente hegemônica, positiva e integradora dos diferentes e desiguais grupos sociais que configuraram e que ainda configuram a sociedade brasileira.

Recentemente, pesquisadores de diferentes campos das ciências sociais e humanas, buscam reconstruir as narrativas subalternas existentes sobre estas festas e rituais, numa tentativa de reescrever as histórias e as antropologias dos hábitos e das gentes deste país. Com esta outra forma de questionar a realidade social, busca-se por reescrever contrastivamente, as formas de viver e atuar em um mundo social (o brasileiro) em que as tensões foram e continuam a ser historicamente encobertas por enunciados "hegemônicos" de democracia racial e igualdade social.

\footnotetext{
${ }^{3}$ Trecho da Alvorada cantado pelas caixeiras da Casa de Fanti-Ashanti do Maranhão - Caixeiras do Divino Espirito Santo. In: Documentos sonoros brasileiros, acervo Cachoeira! CD, 2002. 
A utilização de textos escritos, orais e imagéticos recentes e aqueles preservados em bibliotecas, viabiliza o conhecimento de valores e sentidos que configuram um repertório de significados e práticas subalternas e, contribue para interpretar as modificações (atualizações) ou permenências dos rituais e festas e, de suas alegorias. Com isso, tenta-se uma possivel reconstrução e posterior compreensão à respeito dos jeitos destas práticas e destas gentes nos seus contextos e sua dinâmica (movimentos) em meio aos processos de modernização da sociedade brasileira. Todavia uma interpretação que consiga construir outras narrativas distintas daquelas hegemônicas, cuja pregnância emudecem as performances e fórmulas utilizadas nas representações das culturas populares (sublaternas).

A questão a respeito das classificações de cultura popular tem longo trajeto e possui suas origens nas práticas inglesas de coleta de diferentes manifestações "populares" ou tradicionais (como narrativas tradicionais, costumes tradicionais, sistemas populares de crenças e formas de linguagem, entre outros temas) no século XIX (RODRIGUES, 2003) ${ }^{4}$. Passando pelas abordagens romanticas alemães do mesmo período, que viam nestas manifestações populares a expressão da pureza de um povo ou nação, sendo este argumento utilizado como o enunciado subjacente às narrativas nacionalistas ou de construção e estabelecimento dos Estados-nação. As disputas entre os ilustrados alemães e franceses entre as terminologias cultura e civilização, estabelecem a dicotomia teórica que imprime à noção de cultura popular sua mais profunda marca, a saber: sua localização de oposição em um contínuo entre a cultura culta-popular. Numa forma de eco da disputa cultura-civilização.

A oposição culto-popular se dá no mesmo momento em que os artistas liberais (não mais mestres artesãos) reivindicam para as belas artes o estatuto de autonomia e assim, constroem a hierarquização entre os gestos humanos de intreferência estética ou ética no mundo social, ou seja, colocam de um lado os artistas e de outro os oficiais. Esta divisão é gerada e geradora do "campo da arte", i.e. de processos de legitimação (como a formação dos ateliês, as escolas de arte, as mostras e exposições), de circuitos de circulação e consumo (como a institucionalização dos museus e galerias, as revistas especializadas, leilões, entre outros), de agentes legitimadores (como os críticos de arte, os intelectuais e acadêmicos ligados a escrita de um tipo de história da arte,

\footnotetext{
${ }^{4} \mathrm{O}$ termo folklore, de acordo com Rodrigues (2003), foi cunhado em 1858 pelo inglês William John Thoms, em uma carta enviada à revista The Atheneum, de Londres. Nesta carta Thoms associa este termo aos saberes populares em processo de desaparecimento. Sendo o procedimento de coleta e registro a forma pela qual (ou, o método através do qual) estes saberes deveriam ser preservados, constituindo assim uma ciência nova: a ciência do Folklore. Sobre a conceituação de folclore, entre muitas possibilidades de indicação bibliográfica, o texto de Rodrigues é recomendado por sua linguagem acessível.
} 
marchands e animadores culturais) e de consumidores (formados por colecionadores, galeristas e apreciadores). Desta forma, a tensão entre os gestos estéticos realizados por não especialistas e especialistas formados a partir de uma tradição em processo de criação e legitimação, afirma-se como dinâmica constituidora e arena de disputas econômicas, simbólicas e políticas entre os polos culto-popular.

Esta relação torna-se mais complexa no decorrer do século XX com a caracterização dos gestos estéticos subalternos como simulacros ideológicos em determinados momentos dos Estados capitalistas e em outros, socialistas; como por exemplo o uso do construtivismo ou do realismo revolucionário na então União Soviética ou a incorporação de artistas modernos pelas agências de publicidade estadunidenses. Tensão que pode ser configurada a partir da dicotomia apresentada (CHAUÍ, 2007), da seguinte forma: a arte para o povo ou arte do povo. Esta formulação da questão, tendo por bases as ideologias marxistas, em meio aos movimentos contraditórios por que passou o Século $\mathrm{XX}$, vai constituir um lugar do popular (subalterno) relacionado aos grupos periféricos dos centros urbanos, trabalhadores (operários), ou então aos movimentos artísticos contra-culturais ou mesmo "revolucionários", que estariam em contradição com os meios massivos gerenciados pelos Estados (ARANTES, 2004), deslocando do até então popular relacionado como o tradicional ou com os saberes de um tipo de tradição.

O ponto de inflexão, nesta vorágine que engole a noção de cultura popular (subalterna), são os gestos e ações estéticas realizadas pelas comunidades, grupos ou sujeitos localizados nas bordas desta arena de conflitos. São as manifestações da cultura popular (subalterna) que tem por expressão material as performances, fórmulas de tratamento, festas, rituais, narrativas, sistema de objetos e formas de produção que mediados pela tradição, configuram-se como objetos cotidianos e ideológicos (VILLORO, 2007; p. 9) . Todavia tradição aqui não é simplesmente o repasse de práticas cotidianas, mas ação de compartir significados e signos abstratos, objetos e formas de materializá-los que guardam sentidos para seus produtores e consumidores, e que estão em movimento de transformação, atualização, relocalização e descarte, mas que de alguma forma resguardam uma memória dos objetos criados anteriormente e por conseqüência resguardam uma lembrança das estruturas materiais e espirituais das gerações anteriores (ORTIZ ANGULO, 1990; p. 84).

\footnotetext{
${ }^{5}$ Por ideologia estou de acordo com a proposta de conceituação de Villoro, que ao refletir sobre a dupla função que exercem as crenças coletivas em uma sociedade sometida a uma estrutura de dominação, realiza uma revisão histórica, teórica e metodológica deste conceito. Desta forma, o conceito de ideologia se definiria por sua função objetiva nas lutas sociais para a obtenção ou manutenção do domínio sobre um grupo, assim como o seu condicionamento social. Portanto ideologia se refere não ao conjunto de enunciados falsos, mas às crenças determinadas socialmente, todavia não necessariamente verdadeiras ou falsas; sendo assim, um conceito sociológico.
} 
Em meio à possibilidade de encarar as formas de estar e viver o mundo social das gentes deste país, procuro problematizar a noção de cultura popular a partir das indicações encontradas no texto "O conceito e a tragédia da cultura" de George Simmel (1998). Meu propósito pode ser expresso na apresentação de algumas notas iniciais para a relfexão sobre o conceito e a tragédia do que se tem classificado como cultura popular.

As imagens que a leitura daquele texto de Simmel permitem construir, ajudam a entender a cultura popular sob outros regimes de significados, ou seja, em um outro topus. E nesta outra geografia encontrar novos relevos onde é possível visualizar significados também novos, ou seja, permite dar voz a outros enunciados. O movimento de mapear este novo relevo se dá assistemáticamente e expõe os diferentes cronotopos (AMORIM, 2006) sobrepostos, ou ao modo simmeliano permite abordar a questão de forma ensaística.

Apoio estas novas imagens em uma semiótica figurativa (GREIMAS, 2004) não mais da imitação - ou icônica - que tem no reconhecimento do naturalmente motivado a sustentação para a realidade; mas em uma semiótica da possibilidade de significar, onde os textos/imagens não são, senão através de sua análise e instauração, dito de outra forma, através de sua semiose. ${ }^{6}$

Esta operação - a semiose greimasiana - poderia ser aproximada do diálogo bahktiniano. Este por sua vez, entendido enquanto um processo de comunicação heteroglóssica entre diferenças simultâneas, que excede ao momento de troca - o tempo do diálogo - e institui significados sociais dinâmicos (CLARK \& HOLQUIST, 2004). Por heteroglóssico quero refereir-me a heterogeneidade da enunciação, dito a partir do repertório da lingüística, refiro à complexidade multiforme manifestada na parole. Para Bahktin a liguagem (a comunicação) é um fenômeno que transborda ao sistema abstrato da língua, ela radica na criação coletiva, que tem por origem o "diálogo cumulativo entre o "eu" e o outro, entre muitos "eus" e muitos outros" (STAM, 1992); mediados por fatores contextuais como geração, classe, raça, gênero e contextos, configurando uma arena de narrativas onde cada enunciado disputa e está sujeito às formas de pronúncias, entonações e elusões conflitantes.

Uma das metáforas simmelianas que instaura a possibilidade de significar a cultura popular é aquela que configura a cultura como uma ponte inconclusa. Através desta imagem, Simmel permite configurar o processo de objetivação dos valores significativos para a constituição da personalidade, enquanto um movimento humano de se realizar e desfazer-se. Uma contínua obra em construção e descontrução de práticas e significados, de estéticas e éticas, por fim de ideologias. É este movimento que permite ao espírito constituir sua inteireza, ou numa utilização dos termos simmelianos, constituir a totalidade da sua personalidade.

${ }^{6}$ (...) vale dizer, [que a semióse é] uma operação que, conjungindo um significante e um significado resulta na produção de signos[-objetos] Greimas (2004; p. 80). 
Todavia esta totalidade não é estática, mas sim agente, dialógica, prenhe de possibilidades que não reside na fixação dos conteúdos das realizações humanas, ou como diria Simmel, das objetivações do espirito. Ao invés disso, na justa parcela de vontado para ultrapassar àqueles conteúdos e reconhecer significados, práticas, éticas e estéticas outras que são instauradas a partir da presença física de um "eu", simbólico, histórico e político em face de um outro também físico, simbólico, histórico e politico com quem com-vivo.

Através desta imagem e deste movimento contido na metáfora da ponte que é esvaziada ao tocar o outro lado, o conceito de cultura popular pode realizar-se e desfazer-se. Ou ainda, ao radicalizar o movimento desfazer-se para então realizar-se. A modo de perceber este movimento radical, proponho expor que o conceito de cultura popular ainda é significado por artistas, intelectuais, críticos e negociadores de arte, veículos massivos e a sociedade como a legitima manifestação do povo, o universo da criação subalterna, o lugar de um tipo de pureza e do anonimato. Um exemplo são so textos divulgados no marco da Mostra dos 500 anos do descobrimento do Brasil (AGUILLAE, 2000), ou os documentos produzidos por alguns orgãos de gestão e guarda de Patrimônio Cultural, como o catálogo do Museu de Folclore Edson Carneiro, que carrega o peculiar título "Sondagem na Alma do Povo" (BISILLIAT, 2005).?

Esta instauração de significados históricamente atribuídos aos sistemas de objetos artesanais e legitimados por uma teoria social, conforma a tragédia do conceito de cultura popular. Isso, pelo fato de atá-lo a um conteúdo irremovível e homogêneo, que configura sua representação e dirige sua performatividade, ordena e hierarquiza suas partes, dá-lhe forma, sentido e direção, dito de outra forma, distancia autor de práticas sociais, formas sociais de produção de objetos, imprime, tanto na carne dos sujeitos como na matéria dos objetos um conteúdo inalterável, universal ${ }^{8}$. Dito de outra forma, ainda estamos a sondar na alma do povo!

A tensão que envolve a tragédia do conceito de cultura popular se instala no conflito do "eu" em relação a um outro e ao mundo. Conflito em que a produção dos significados se confronta na ação de dissipar as outras vozes/imagens contidas no popular. Vozes que vitalizam o espírito, permitem o caminho da alma em si em direção de si mesma, na busca pela pluralidade de significado(s); ou com queria Simmel, pela cultivação; mas chamo a atenção que o termo que utiliza Simmel é cultivação e não ilustração. Com este termo/signo, Simmel abre a fissura que autoriza a qualquer um organizar dos sentidos encontrados nas e através das coisas cotidianas e com isso expor as multiplas versões a respeito dos enunciados e textos lidos.

\footnotetext{
${ }^{7}$ Sobre as questões relacionadas com o anonimato, ou ainda sobre o papel ideológico de pureza e identidade associados aos sistemas de objetos subalternos (populares) (ver PRICE, 2000; GARCIA CANCLINI, 1983; LAUER, 1983).

${ }^{8}$ Para narrativas outras sobre o conceito de cultura popular, ver Barbosa (1999) e Ayala e Novais (2003). 
Não encerrando nos "especialistas" as chaves para a (re) construção do mundo simbólico e por conseqüência do material, Simmel constroe a ponte que faz como que os saberes não hegemônicos compartam a arena de disputas que configuram as imaginações de homens e mulheres nos diferentes contextos sociais.

Seguindo ainda a indicação de Simmel, a tragédia da cultura é ter em si os processos e conteúdos que a afastam de sua finalidade, ou seja, a cultura contém em sua figuração conteúdos ilusórios. Todavia, e pensando a partir das reflexões de Bahktin sobre a carnavalização (BAHKTIN, 2002), e indo a contrapelo de Simmel, a instauração de significados destas figurações/imagens/ signos simultaneamente possibilita a reflexão e a refração (BAHKTIN, 2006) daqueles conteúdos. Este duplo movimento por sua vez, permite que a ordem seja invertida e que os conteúdos operadores da configuração do conceito sejam postos em questão ou mesmo subvertidos. A novidade é que a inversão sempre traz consigo uma nova possibilidade de singificação do signo e conseqüentemente de interpretação, questionando assim, a fixidez dos conteúdos e ao mesmo tempo, carnavalizando a tragédia contida na configuração a cultura popular. Em outras palavras, o anônimato, a falta de historicidade, a "essência" (conteúdos estáticos e configuradores do conceito hegemônico de cultura popular) contidos no conceito podem ser, e continuamente são, dessacralizados em função das imaginações e gestos estéticos e éticos de homens e mulheres atores de suas histórias e historicidades pessoais e coletivas em meio as intertextualidades culturais.

\section{Nem saídas, nem fim. Talvez começos...}

Radicalizando mais uma vez, faz necessário encerrar configurando o movimento realizado até aqui, registrando sua rota e com isso, dando (mesmo que provisóriamente) a sua forma: circular, ou circuladora. Afirmo que o conceito de cultura popular, enquanto signo pertencente a um regime de significados que pode se abrir para significar os gestos estéticos e éticos criados e experimentados por grupos subalternos, históricos, políticos. Ou utilizando uma interesante metáfora de Geertz (1997), permite expor a construção e reconstrução de possibilidades não hegemônicas de estar neste mundo e dele participar ativamente a partir dos seus subúrbios.

A inventividade desta outra metáfora permite pensar em cartografias que inscrevam a cultura popular em seus profundos conflitos e reconstruções de sentidos, o que configura novas imagens possíveis tanto dos sujeitos quanto das manifestações populares. Imagens que contenham as tensões expressivas e as contradições existentes em qualquer forma (maneira) de ser humano e coletividade, mas, nem por isso isenta de multiplos significados e significações, 
tal qual o retrato de Dora Mäar de Picasso ou o trecho do poema de Haroldo de Campos, encontrado em seu mapa das galáxias transformadas em profundos atos de fala; e é com ele que encerro:

[...] o povo é um inventalínguas, na malicia da ma-
estria no matreiro da maravilha no visgo do impro-
viso tenteando a travessia azeitava o eixo do sol
Circulador de fuló, ao Deus ao demodará Que Deus
te guie por que eu não posso guia Ê Eida que já me
deu, circuladô de fulo inda que falta me dá.

\section{Referências bibliográficas}

ABREU, M. As memórias do divino. Discussões sobre a festa popular e representações da identidade nacional a partir dos registros sobre as comemorações do Divino Espírito Santo na cidade do Rio de Janeiro do Século XIX. Revista do Patrimônio Histórico Nacional, 28: 40-59, 1999.

AGUILlaE, N. (Org.). Mostra do descobrimento. Fundação Bienal de São Paulo. São Paulo: Associação Brasil 500 anos - Artes Visuais, 2000.

AMORIM, M. Cronotopos e exotopia. In: B. Brait (Org.). Bahktin: outros conceitos-chave. Pp. 95-113. São Paulo: Contexto, 2006.

ARANTES, A.A. O que é cultura popular. São Paulo: Brasiliense, 2004.

AYALA, M. \& NOVAIS, M.I. Cultura popular no Brasil. Perspectiva de análise. $2^{\mathrm{a}}$ Edição. São Paulo: Ática, 2003.

BAHKTIN, M. A cultura popular na Idade Média e no Renascimento. O contexto de François Rabelais. São Paulo: Annablume, 2002.

BAHKTIN, M. Marxismo e filosofia da linguagem. São Paulo: Hucitec, 2006.

BARBOSA, W. de D. O Artesanato indígena e os "novos índios" do Nordeste. Revista do Patrimônio Histórico e Artístico Nacional, 28: 199-215, 1999.

BISILLIAT, M. (Coord.). Museo de Folclore Edison Carneiro: sondagem na alma do povo. São Paulo: Empresa das Artes, 2005.

BRANDÃO, C.R. O que é folclore. São Paulo: Brasiliense, 2003.

CAMPOS, H. de. Galáxias. São Paulo: Editora 34, 2004.

CHAUÍ, M. Cultura e democracia. 12ª Edição. São Paulo: Cortez, 2007.

${ }^{9}$ Trecho do poema Circuladô de Fulô. Campos 2004. 
CLARK, K. \& HOLQUIST, M. Mikail Bahktin. São Paulo: Perspectiva, 2004.

DOCUMENTOS SONOROS BRASILEIROS. Acervo Cachoeira! (CD). São Paulo: Itaú Cultural e Associação Cultural Cachoeira, 2002.

GARCIA CANCLINI, N. Culturas populares no capitalismo. São Paulo: Editora Brasiliense, 1983.

GEERTZ, C. O saber local. Petrópolis, RJ: Vozes, 1997.

GREIMAS, A.J. Semiótica figurativa e semiótica plástica. In: A.C. de Oliveira (Org.). Semiótica plástica. Pp. 75-96. São Paulo: Hacker Editores, 2004.

LAUER, M. Crítica ao artesanato: plástica e sociedade nos Andes peruanos. São Paulo: Nobel, 1983.

MORAES FILHO, E. de. Introdução: formalismo sociológico e a teoria do conflito. In: E. de Moraes Filho (Org.). Georg Simmel: Sociologia. São Paulo: Ática, 1983.

ORTIZ ANGULO, A. Definición y clasificación del arte popular. México D.F.: INAH, 1990.

PRICE, S. Arte primitiva em centros civilizados. Rio de Janeiro: Editora da UFRJ, 2000.

SIMMEL, G. O conceito e a tragédia da cultura. In: J. SOUZA \& B. ÖELZE (Orgs). Simmel e a modernidade. Brasília: Editora da Universidade de Brasília, 1998.

STAM, R. Bahktin. Da teoria literária à cultura de massa. São Paulo: Ática, 1992.

VOLLORO, L. El concepto de ideologia y otros ensayos. $2^{\text {a }}$ Edição. México: Fondo de Cultura Económico, 2007. 